\title{
Letras - uma área em busca de justificativa
}

Regina Zilberman ${ }^{a}$

\begin{abstract}
Resumo
A área de Letras conta com uma longa trajetória e célebres precursores, como Platão, Aristóteles e Quintiliano. O período de seu apogeu coincidiu com a supremacia dos estudos de História da Literatura, consagrando autores que se tornaram canônicos. Atualmente, experimenta notável esvaziamento político e perda de clientela, sugerindo que sua permanência depende do encontro e estabelecimento de novas parcerias.
\end{abstract}

Palavras-chave: Letras; História da Literatura; Ensino da Literatura. 


\section{Os pioneiros e os bons tempos}

Entre os pioneiros dos estudos literários, podem-se identificar três nomes bastante ilustres da Antiguidade: Platão e Aristóteles, entre os helênicos, e Quintiliano, entre os latinos. Os três, à sua época, escreveram tratados sobre poesia: Platão, que nem sempre teve boa vontade para com os artistas, é autor de diálogos em que epopeias, dramas e hinos estão no centro de suas reflexões, mesmo quando essas se misturam com a metafísica e a ética. Aristóteles, na Poética sobretudo, sintetizou um saber que conferiu à criação com palavras um status elevado, ainda que secundário diante do universalismo da filosofia.

Ambos foram professores, tendo difundido suas ideias junto aos estudantes que frequentavam a Academia ou o Liceu. Quintiliano, na esteira dos filólogos helenistas e latinos (Teofrasto, Dionísio Trácio, Demétrio, Dionísio de Halicarnasso), redigiu as Instituições Oratórias, obra que, graças a seu prestígio e influência entre os estudiosos medievais, garantiu a sobrevida da arte literária mesmo quando a cultura e o conhecimento ficaram submetidos aos ditames da Igreja e aos pressupostos teológicos dos difusores do pensamento cristão hegemônico (CARPEAUX, 1959, p. 15-16).Precisaram eles justificar, junto à sociedade ou a seus dirigentes, por que exerciam essas atividades docentes e especulativas, teóricas e práticas, orais e escritas?

Ainda não dispomos de mecanismos apropriados para aferir a recepção desses pioneiros em seu tempo. Sócrates, nos últimos anos do século $\mathrm{V}$ e primeiros do século IV a. C., também ele professor e filósofo, foi criticado por uns (Aristófanes, por exemplo) e venerado por outros, como Platão, seu principal discípulo, e Xenofonte. Todavia, acabou na prisão, obrigado ao suicídio, após a acusação de perverter a juventude a quem transmitia seus conhecimentos. De Platão e Aristóteles, sabemos pouco, apenas que tiveram de perambular pela Grécia, além da Sicília, no caso do primeiro, e, no do segundo, pela Macedônia, exercendo suas atividades pedagógicas.

Suas ideias, porém, atravessaram os séculos, com sucesso variado em épocas distintas. Platão foi resgatado por Plotino e adaptado por Agostinho de Hipona, quando formulou sua concepção de $A$ cidade de Deus. E Agostinho foi, também 
ele, professor de Retórica, antes, contudo, de converter-se ao Cristianismo. Aristóteles aguardou um pouco mais, porém, apropriado por Tomás de Aquino, amparou teoricamente a construção da Suma Teológica, obra que, desde o título, explicita sua ambição. Traduzida a Poética para os vernáculos europeus, a partir do século XVI da Era Cristã, tornou-se o paradigma dos estudos literários nas versões que esses tomaram ao longo dos séculos.

Essa "virada", para se utilizar o termo de Greenblatt (2012), empregado para designar o impacto causado pela tradução da obra Da natureza das coisas, de Lucrécio, no século XV, foi fundamental para os estudos literários desde o Renascimento. Ele, pode-se dizer, respaldou o ensino da poesia, que, naquela altura, já se chamava literatura, em todos os níveis em que seu estudo acontecia. Não que o ensino da literatura acompanhasse o estudante desde os primeiros anos, já que o pressuposto era o de que cabia antes alfabetizar crianças e jovens, para, depois, alçá-las aos produtos mais elevados da arte com a palavra.

Assim, ao lado da circulação - quase obrigatória - da Poética (e também da Retórica) na escola, de modo direto ou em versões disseminadas por manuais didáticos, deu-se a valorização da Literatura como manifestação excelente da linguagem verbal, digna de ser imitada por todos que a praticavam.

Seria adequado afirmar que, nos séculos que anunciavam e implantavam a modernidade, a área de Letras apareceu, cresceu, fortaleceu-se e impôs-se?

Talvez sim, ainda que não estivesse desenhada por meio de instituições universitárias, dirigidas especialmente à sua docência e difusão. $\mathrm{O}$ ensino da Literatura acontecia antes e fazia parte da formação do jovem (mas não da jovem), compondo o catálogo de conhecimento que cabia dominar e praticar, independentemente de sua qualificação ou futuro profissional.

Por sua vez, o êxito do ensino da Literatura e, por consequência, da área de Letras não pode ser desvinculado das seguintes circunstâncias:

a) ensinava-se, isto é, difundia-se a produção clássica, procedente da Antiguidade greco-latina, aquela que fora contemporânea, por exemplo, de Platão, Aristóteles e 
Quintiliano, mas que era passado para os consumidores do presente.

A produção do presente tornava-se aceitável quando acompanhava normas e ditames das obras originárias daqueles períodos, explicando-se por que se experimentou, por alguns séculos, estendendo-se até o XIX, a prevalência de gêneros como a epopeia e a tragédia moldadas nos exemplos de Homero e Virgílio, em um caso, de Sófocles e Eurípedes, em outro.

b) Esse ensino era dirigido, sobretudo, à elite, definida por sua pertença à aristocracia ou à alta burguesia. Mulheres podiam ser educadas, desde que adequadas aos padrões socioeconômicos dominantes. Entretanto, no que diz respeito às Américas, africanos, afro-americanos ou nativos americanos, apenas em circunstâncias excepcionais e em conformidade com coordenadas similares eram incluídos nesse quadro (QUIJANO, 2000).

A Literatura gozava de prestígio, e seu ensino não era uma opção; porém, a circulação era restrita, e não universal, de uma parte, porque se privilegiavam modelos poéticos pretéritos, de outra, porque se dirigia a segmentos sociais previamente determinados.

Contudo, mesmo assim, essa era dourada não teve continuidade, gerando a necessidade de novos processos de autojustificação.

\section{A razão prática}

Nãoé demais lembrar as profundas mudanças verificadas durante o século XVIII, período marcado pelas revoluções derivadas dos processos de modernização em desenvolvimento desde o século XV (WILLIAMS, 1980):

a) a revolução econômica, expressa nos efeitos da Revolução Industrial, a que se associam intensas modificações no âmbito tecnológico;

b) a revolução política, sintetizada nos ideais igualitários da Declaração dos Direitos do Homem e do Cidadão, de 1789, de que resultou a busca de um sistema democrático de representação popular no Estado (HUNT, 2009); 
c) a revolução do saber, caracterizada pela valorização do conhecimento e da ciência, entendida essa como resultante de uma metodologia empírica de permanente experimentação e validação.

O Iluminismo parece ser a corrente de pensamento que congrega os ideais dessas distintas revoluções. A circunstância de ele abrigar vertentes variadas e propostas difundidas em espaços e sociedades dessemelhantes sinaliza o caráter polifônico e liberal do movimento. A denominação acolhe conceitos não necessariamente harmônicos e pensadores nem sempre complementares. No entanto, alguns traços seus podem ser apontados, destacando-se pelo menos três deles:

a) a permanente busca de aperfeiçoamento - ou de amadurecimento -, como define Emanuel Kant no inquérito sobre o tema a que responde em 1783;

b) a recusa do preconceito e das ideias prontas, logo, da ortodoxia religiosa, que se impunha desde os séculos XV e XVI por meio da violência e do arbítrio, de que é exemplo a Inquisição;

c) a aspiração à liberdade, associada ao reconhecimento dos direitos humanos e à recusa da servidão, fosse ela econômica, étnica ou colonial.

Por outro lado, o Iluminismo instaurou o culto à ciência, a ponto de, muitas vezes, colocá-la no lugar da religião, como sugerem movimentos como a Maçonaria, em expansão e fortalecimento desde o começo do século XVIII, ainda que combatida pela Igreja e pelo Estado (MOREL, 2001). Ao lado da ascensão da ciência, tem-se a da tecnologia, estando, muitas vezes, a primeira a serviço da segunda, em razão, sobretudo, das necessidades econômicas advindas da industrialização. Melhorar a produtividade pode não ser ainda palavra de ordem, mas essa premissa está presente nas distintas ações dos pesquisadores que buscam meios de extrair vantagens do mundo físico na busca de ganhos monetários.

A valorização da ciência, em razão de sua colaboração com o desenvolvimento tecnológico, traz consigo um posicionamento pragmático: pesquisa-se o que pode ser útil, 
até mesmo quando não se percebe com muita clareza em que o conhecimento adquirido poderá ser aplicado. Estudos sobre os precursores da Informática têm particular apreço por localizar, em ações datadas do começo do século XIX, os primeiros passos na direção da invenção do cérebro eletrônico e de seu avatar, o computador (GLEICK, 2013).

O pragmatismo não é prerrogativa do cientificismo emergente nos séculos XVIII e XIX. A formação socioeconômica decorrente da Revolução Industrial - a saber, a burguesia e o capitalismo - orienta-se pela razão prática e, sobretudo, pelos resultados imediatos. A investigação exclusivamente especulativa está com os dias contados nas primeiras décadas do século XIX. Não por acaso, a Metafísica experiencia seus últimos arranques na obra de Hegel, a partir da qual Karl Marx constrói seu pensamento materialista, talvez um dos derradeiros modelos totalizantes, com pretensões universalistas, do pensamento ocidental.

Onde fica o mundo do intelecto e da arte? Não ficou esquecido, pois o século XVIII presenciou também o estabelecimento da Estética, com o fito de refletir sobre o conceito de Beleza e entender as relações entre o sujeito e o objeto estético. Emanuel Kant (1995), o teórico da Aufklärung alemã, é também o pensador que sintetiza o conceito doravante vigente de arte como uma "finalidade sem fim". Vale dizer, o oposto do - mas não a oposição ao - pragmatismo das ações exercidas na sociedade.

A separação entre a arte e a vida prática parecia uma boa solução, pois significava o reconhecimento da condição autônoma da primeira. A vida prática justifica-se em função do que produz; a arte produz sem se justificar. Preservavase a especificidade de seu domínio, oferecia-se uma ciência para refletir sobre ela, proporcionava-se aos artistas ampla liberdade para criar. Só não era respondida uma pergunta: o que fazer com isso?

No contexto da vida burguesa, uma única resposta seria possível: ganhar dinheiro. Ser - e bem - remunerado. Contudo, como avaliar o produto artístico? De um modo bastante simples: postulando o "valor estético" que, supostamente, deveria coincidir com o "valor econômico". Desse modo, mantinham-se os privilégios da arte como segmento autônomo, afiançava-se a validade de uma ciência habilitada a avaliar os 
produtos - a Estética e, depois, a crítica da arte / literária -, e apresentava-se uma resposta coerente com os critérios de funcionamento da própria sociedade (WOODMANSEE, 1994).

Como se sabe, a equação não deu muito certo. A Estética amparava uma ciência e uma prática, a de julgar os produtos tidos como artísticos. Não, porém, a de medir financeiramente aqueles produtos. Assim, não ultrapassava o círculo que traçara, ao partir de uma premissa a ser tão somente confirmada diante de um universo de objetos estéticos. Eis a tarefa assumida e praticada pelos Estudos Literários. Apoiados, contudo, na noção da "finalidade sem fim", ficam de mãos vazias quando precisam justificar sua existência.

Por isso, coube buscar outro caminho, novo, mas ainda coerente com os rumos da ciência em voga: o da História da Literatura.

\section{A História da Literatura}

Que a História da Literatura poderia requerer a qualificação de "ciência", sugere-o Giambattista Vico, cuja Ciência Nova, de 1725 e revista em 1744, garantiu o status epistêmico das investigações relativas aos "fatos e eventos no tempo" (FIKER, 1994, p. 35). Não por coincidência, datam do século XVIII as obras destinadas a prestar contas do percurso cronológico da literatura de uma certa região (território, nação ou país), como são as Histoire littéraire de la France, de 1733, e a Historia literária de España, de 1766.

Provêm também desse período as indagações sobre as origens, em uma época em que se entende a trajetória da sociedade e da humanidade como réplica ou duplicação da história biológica do ser humano, construída em termos progressivos que avança da infância à juventude e maturidade, depois regride em decorrência da senilidade, chegando ao declínio (WHITE, 1986). A visão evolucionista remonta a Vico e fundamenta as obras que narram esses começos, como procede o Tratado sobre a origem da linguagem, de Johann Gottfried von Herder, de 1770.

A emergente História da Literatura une os pontos: expõe o trajeto da literatura de uma nação ou de um povo, descrevendo seu estágio inicial e seu crescimento ao longo do tempo, na direção do aperfeiçoamento, conforme o 
figurino iluminista explicado por Kant. Desde o título, a Geschichte der Literatur von ihrem Ursprung bis auf die neuesten Zeiten ("História da Literatura de suas origens até os novos tempos"), de Joseph Eichhorn, publicada entre 1805 e 1812, ilustra a concepção e o método dela derivado, segundo os quais a trajetória de uma nação e de sua produção literária estão relacionadas e evoluem em paralelo.

Pode-se medir o sucesso da História da Literatura por meio do número de obras destinadas a catalogar a trajetória da produção escrita de países emergentes. Por meio de coletâneas, florilégios, parnasos, bosquejos, povoou a bibliografia, especialmente a latino-americana, na aurora das independências nacionais. Além disso, foi apropriada pela escola: no Brasil, o estudo da Retórica foi paulatinamente substituído pela Historiografia, e muitos pesquisadores renderam-se ao mercado didático: Silvio Romero converteu sua História da Literatura Brasileira, de 1888, no Compêndio de História da Literatura Brasileira, de 1906, título utilizado um ano antes por Coelho Neto em livro focado no público estudantil.

Hans Robert Jauss (1969) chama a atenção para o paradigma historicista que, nascido na época do Romantismo, amparou o sistema escolar por longo tempo. No Brasil, podese afirmar que ainda vigora tal paradigma, sobretudo no ensino superior, moldado em grande parte pela perspectiva historiográfica que encontra na cronologia seu principal suporte e na ótica evolucionista sua visão de mundo.

Não se trata, porém, de tão somente avaliar - e talvez rejeitar - a concepção positivista que preside essa narrativa. Trata-se também de entender que literatura é essa que a História da Literatura privilegia. Não é difícil identificá-la, pois os estudos de gênero e de raça já chamaram a atenção para o teor discriminatório que fundamenta aquela narrativa: predominam os sujeitos brancos e masculinos, sobretudo quando o objeto é o passado do patrimônio artístico nacional. Como a História da Literatura prefere o passado ao presente, converte-o em canônico e paradigmático, reforçando a exclusão. É diante desse pano de fundo que se fazem a transmissão e o ensino da literatura, concedendo às exceções - mulheres afro-brasileiras, como Maria Firmina dos Reis, por exemplo - o espaço das brechas, insuficientes para se transformarem em normas. 
O conhecimento da História da Literatura vem escorando e justificando a área de Letras desde que ela se constituiu no Brasil, tendo como missão constatar, descrever e afiançar a identidade nacional. Documentos oficiais, emanados do Ministério da Educação, como os Parâmetros Curriculares Nacionais, as Orientações Curriculares para o Ensino Médio ou a controversa Base Nacional Comum Curricular questionam a prevalência dos estudos historiográficos, mas reconhecem, como se registra nas Orientações curriculares para o Ensino Médio (Linguagens, Códigos e suas Tecnologias), que cabe considerar a História da Literatura "uma espécie de aprofundamento do estudo literário, devendo, pois, ficar reservado para a última etapa do ensino médio ou para os que pretendem continuar os estudos especializados" (MINISTÉRIO DA EDUCAÇÃO, 2006, p. 77).

Assim, essa escada parece não poder ser retirada, sob pena de sacrificar o edifício inteiro da área de Letras.

\section{Cogitando alternativas}

Aparentemente, não somos apenas nós, brasileiros, que nos preocupamos com o destino dos estudos literários no âmbito da escola, em nível médio ou superior. Em 2007, Tzvetan Todorov, figura de proa do Estruturalismo e Pós-estruturalismo francês, lançou o ensaio La littérature en péril ("A literatura em perigo"), que obteve rápida repercussão e várias traduções. Um ano antes, em 30 de novembro de 2006, outro autor, Antoine Compagnon, em conferência no Collège de France, perguntou a si mesmo e ao público: La littérature, pourquoi faire?, exposição publicada em 2007 e traduzida, no Brasil, em 2009, com o título Literatura para quê? Em 2008, o escritor François Begaudeau protagonizou o filme baseado em seu livro, Entre les murs, de 2006, dirigido por Laurent Cantet, situado em uma escola de periferia, destinada a jovens originários das camadas populares. Em 2009, a romancista Danièle Sallenave lançou Nous, on n'aime pas lire, relatando a atividade desenvolvida durante um semestre letivo entre estudantes de Marselha, a maioria descendente de imigrantes originários da África, em especial das antigas colônias francesas, alcunhados beurs. Para fechar a primeira década do novo século, Vincent Jouve, em 2010, reintroduziu o problema sob a forma de pergunta, 
indagando: Por que estudar literatura?, livro traduzido para o português em 2012.

A preocupação desses intelectuais e artistas coincide em alguns pontos: os jovens não gostam de ler; a escola é espaço de conflito - cultural, étnico, etário -, e não de sintonia e aprendizagem; a literatura está ameaçada de desaparecimento ou, então, requer justificativa, em sala de aula e na sociedade.

Diante de tais constatações, Compagnon (2009, p.20) lança a pergunta crucial: "Por que defender sua [da literatura] presença na escola?". Após diagnosticar que "o espaço da literatura tornou-se mais escasso em nossa sociedade há uma geração", sinaliza que uma dessas perdas dá-se no âmbito da escola, "onde os textos didáticos a corroem, ou já a devoraram" (COMPAGNON, 2009, p. 21), determinando a importância de explicar a necessidade da leitura tanto por parte dos letrados profissionais (professores, críticos e escritores), quanto por parte dos indivíduos não necessariamente vinculados ao campo intelectual: "Doravante a leitura deve ser justificada. Não somente a leitura corrente, do leitor, do homem de bem, mas também a leitura erudita, do letrado, do/da profissional." (COMPAGNON, 2009, p. 23) Jouve (2012, p.9), por sua vez, denuncia "uma crise dos estudos literários", que o leva a questionar a própria existência dos cursos de Letras: "de que serve o ensino das Letras? É preciso mantê-lo? Se sim, o que fazer nele?"

As causas atribuídas aos problemas identificados podem diferir. Para Todorov, os métodos de análise literária afugentam os estudantes. Para Begaudeau (2009) e Cantet (2008), o autoritarismo institucional e os preconceitos em relação aos indivíduos das classes mais baixas e aos grupos etnicamente minoritários tornam a escola detestável, provocando a rejeição do que ela transmite, bem como dos sujeitos que a dirigem e a representam. Sallenave (2009) também acusa não só o sistema de ensino de ser incapaz de formar leitores proficientes, mas também os professores, desinteressados em seu trabalho e na leitura da literatura, e os princípios liberais que deixam a decisão sobre estudar e interessar-se por livros quase que exclusivamente por conta do aluno, conforme uma prática proposta por Daniel Penac (1993), que a autora rejeita.

Várias são as razões que permitem compreender o problema. Não é difícil, porém, reconhecer um dado em 
comum: as manifestações não provêm dos docentes, nem dos discentes, mas de representantes do - digamos assim sistema literário: dois escritores (François Begaudeau e Danièle Sallenave), três eminentes teóricos da literatura (Antoine Compagnon, Tzvetan Todorov e Vincent Jouve), além de um cineasta premiado (Laurent Cantet), naquilo que o aparato cultural evidencia de mais acadêmico e canônico.

Outro fator está presente na maioria dos acusadores: a indigitação do local do crime - a escola. Além disso, para culminar, a autópsia da vítima: a literatura, por motivos diversos, mas não incongruentes, "assassinada" em sala de aula ou em vias de desaparecimento, como um produto que transcende a individualidade de cada texto e de cada obra.

A situação não deixa de ser instigante: prestigiados representantes da alta literatura e da cultura francesa, no nível da produção e da recepção, resolvem voltar os olhos para o universo do ensino em geral e da literatura em particular. Ao fazê-lo, parecem cair das nuvens, pois presenciam, primeiramente estupefatos, depois de modo questionador, a paulatina exclusão da literatura na escola ou a distância que se estabeleceu entre ela e os supostos principais interessados: os estudantes.

Não apenas isso: parecem convir que, sem a escola, não há lugar para a literatura no mundo, aquele que supostamente se localiza além das paredes denunciadas no livro e no filme de Begaudeau e Cantet. Por fim, uma derradeira constatação: a de que a literatura não é um ser autônomo, como fizera crer o estruturalismo condenado por Todorov; e, se pode ser independente de autores, impressores, livreiros ou críticos, não sobrevive sem a escola, com a qual tem estabelecida uma relação consolidada pelo tempo e pela história.

Apontado o problema e identificados culpados e vítimas, cabe buscar uma saída. Os franceses optam por uma solução, parece-me, convencional, pois, em seus livros e conferências, propõem a recuperação do papel tradicional da literatura, encarando-a como entidade una e autônoma. Todorov (2009, p.89), por exemplo, convoca os docentes a buscar "acesso ao sentido [das] obras - pois postulamos que esse sentido, por sua vez, nos conduz a um conhecimento do humano, o qual importa a todos". Da sua parte, Compagnon propõe que a literatura 
$\operatorname{dev}[\mathrm{a}]$, portanto, ser lida e estudada porque oferece um meio - alguns dirão até mesmo o único - de preservar e transmitir a experiência dos outros, aqueles que estão distantes de nós no espaço e no tempo, ou que diferem de nós por suas condições de vida. Ela nos torna sensíveis ao fato de que os outros são muito diversos e que seus valores se distanciam dos nossos (COMPAGNON, 2009, p. 47).

Similar crédito manifesta-se no livro de Vincent Jouve, que, ao final, espera "ter conseguido demonstrar que a literatura tem um valor específico", uma vez que "o confronto com as obras - isso é o mais evidente - enriquece nossa existência" (JOUVE, 2012, p. 163).

Pode-se concluir, então, que, aparentemente, nada há de muito novo. Defende-se o estudo da Literatura, porque ela traz consigo componentes singulares de transmissão de saber e experiência que a capacitam de modo especial, tornando-a um ente sagrado a ser acolhido e acatado. Com isso, justificase igualmente a área de Letras, o templo em que se cultiva e preserva aquela entidade aurática. Essa dinâmica reproduz e reitera a concepção fundadora da Estética, que concebeu a arte como um valor autônomo e autoexplicável e encontrou na História da Literatura, particularmente quando aplicada ao ensino, seu canal principal de transmissão. Dessa maneira, ignoraram-se as mudanças por que passou a sociedade desde então, a qual, no âmbito da cultura, experimentou o sucesso da indústria cultural, a extensão da globalização, o apagamento das fronteiras entre gêneros artísticos e a afirmação do hibridismo.

O modelo proposto pelos intelectuais franceses, ao não questionar a parceria de seu conceito de literatura e de seu ensino com uma sociedade dominada pela burguesia, em um sistema capitalista triunfante, expõe seu pendor idealista, ao entender a criação artística como um objeto desvinculado de outros condicionamentos, a não ser o de provocar em seu destinatário - o leitor, que não é definido como um consumidor - uma reação espiritual que o eleva acima da rotina e da acomodação. Ao texto literário é atribuído um poder que advém dele mesmo e que, sem qualquer mediação, alcança o sujeito da percepção que, também ele sem qualquer mediação, absorverá o eventual teor encantatório e simultaneamente transformador do objeto artístico. 
A perspectiva preconizada não é inovadora; pelo contrário, reitera concepções oferecidas pela Estética desde seus primórdios, consolidadas por uma História da Literatura que sobrevalorizou os produtos capazes de provocar efeitos distintos em seus recebedores. Por sua vez, é por esses resultados que a Literatura encontraria sua justificativa, imantando a área que a toma como objeto de estudo.

Contudo, não apenas a literatura, encarregada do cumprimento da árdua tarefa, mas também a área que a escolhe como campo de investigação, igualmente carregando nos ombros pesado fardo, ficaram desamparadas, pois já não basta apelar para critérios que funcionaram em épocas passadas. Por isso, seguidamente buscam-se alternativas externas à Literatura e à área Letras, refletindo, por exemplo, como tal área pode participar de um projeto econômico e social calcado na tecnologia e na ciência aplicada.

Alguns de nós já participamos de comissões específicas ou interdisciplinares em que somos chamados a explicitar como a área de Letras pode adequar-se a propostas de desenvolvimento empresarial, o que a justificaria plenamente no contexto da sociedade industrial que o Brasil ainda almeja ser. Contudo, na falta de se ter o que oferecer ao/à especialista em Letras, não poucas vezes resta o papel de relator de comissões dessa natureza, já que a habilidade técnica que ele domina diz respeito à redação de textos e à correção gramatical.

Trata-se, aqui, de uma caricatura, é claro. Ela ajuda, no entanto, a pensar que o caminho não é esse. Talvez possa ser o de acompanhar não a tecnologia, mas os desenvolvimentos e rumos da produção literária - a brasileira, no caso -, porque essa já elegeu seus novos parceiros e modalidades de circulação, tradicionais ou, até agora, inusitados.

Como se sabe, a produção literária nunca se restringiu apenas à obra impressa, como fazem crer a História e a Teoria da Literatura. Ela convive com a cultura popular responsável pela poesia de cordel, pelas narrativas folclóricas, pelos textos associados à música, à dança e às festas populares; contudo, essas são manifestações reconhecidas apenas marginalmente, seguidamente na qualidade de concessão indulgente. Ao lado delas, pode-se observar a fecundidade dos formatos mistos praticados pela indústria cultural, como a novela de televisão (como já houve a novela de rádio), as histórias em quadrinhos 
e as novelas gráficas, tiras, cartuns, charges. Eis um veio que, embora criativo e compartilhado por muitos escritores integrantes da literatura elevada (a exemplo de Dias Gomes, há algumas décadas, e de Lourenço Muttarelli recentemente), não é incorporado ao patrimônio de que se alimenta o ensino na área de Letras.

Excluídas são igualmente as expressões derivadas de segmentos periféricos ou marginais, nem todas recebidas com agrado pelas autoridades, como grafitis e pichações, a maioria de ordem sincrética, porque resultantes da hibridização de elementos de extração rural e urbana, como o gênero sertanejo, de estilos procedentes do exterior amalgamado a temas nacionais, como o rock, o rap ou o Hip-hop, ou da fusão do tradicional e do novo, como o pagode. Por sua vez, embora valorizada por seus usuários, é ainda ignorada a produção digital, igualmente mista, que se estende desde a transposição do impresso para arquivos virtuais até manifestações exclusivas, transmitidas em redes sociais, como blogues, twitters, publicações no Facebook, YouTube e equivalentes, o que determina o aparecimento de gêneros próprios, como hipertextos, postagens, tweets e games.

A nosso ver, são os protagonistas desse universo da criação os parceiros que a área de Letras pode escolher para sua jornada inovadora. São novos em duplo sentido: de um lado, porque são jovens, ocupando lugares no âmbito da produção, da circulação e do consumo; de outro, porque, sobretudo quando se pensa nas expressões derivadas de segmentos periféricos ou marginais, provêm de coletividades para quem os estudos superiores não se apresentam como horizonte possível, dado o caráter elitista que aqueles assumiram ao longo de nossa história.

À área de Letras não cabe justificar-se diante do poder político, social ou econômico - porque não tem (e talvez nem deva ter) o que oferecer. Em termos de serviços acolhidos por seus usuários tradicionais, ela acabou por se mostrar descartável ou subalterna. Descartável quando se verifica quão fácil é substituí-la por um computador ou um robô, em especial quando é oferecida na modalidade de Ensino à Distância (EaD); subalterna, quando se espera que ela se ajuste a demandas que não partiram de seus processos internos. 
Cabe-lhe, pois, buscar - e com alguma humildade, talvez - novas parcerias entre aqueles e aquelas que nunca a frequentaram, mas que, sujeitos da produção artística, literária e linguística, certamente farão bom emprego dela. Porque as Letras lidam com a linguagem, que é o modo como se dá a inserção de cada indivíduo na sociedade e na arte. Sob esse aspecto, ela pode ser única - e inovadora -, o que é a uma boa razão para explicar sua persistência, resiliência e permanência.

\section{REFERÊNCIAS}

BÉGAUDEAU, François. Entre os muros da escola. Trad. Marina Ribeiro Leite. São Paulo: Martins Fontes, 2009.

CARPEAUX, Otto Maria. História da literatura ocidental. Rio de Janeiro: O Cruzeiro, 1959.

COMPAGNON, Antoine. Literatura para quê? Trad. Laura Taddei Brandini. Belo Horizonte: Editora da UFMG, 2009.

ENTRE OS MUROS da escola. Direção de Laurent Cantet. Produção: Caroline Benjo. Paris: Haut et Court, 2008.

FIKER, Raul. Vico, o precursor. São Paulo: Moderna, 1994.

GLEICK, James. A informação. Uma história, uma teoria, uma enxurrada. Trad. Augusto Pacheco Calil. São Paulo: Companhia das Letras, 2013.

GREENBLATT, Stephen. A virada. O nascimento do mundo moderno. Trad. Caetano W. Galindo. São Paulo: Companhia das Letras, 2012.

HUNT, Lynn. A invenção dos direitos humanos. Uma história. Trad. Rosaura Eichenberg. São Paulo: Companhia das Letras, 2009.

JAUSS, H. R. Paradigmawechsel in der Literaturwissenschaft. Linguistische Berichte 1, p. 44-56, 1969.

JOUVE, Vincent. Por que estudar literatura? Trad. Marcos Bagno e Marcos Marcionilo. São Paulo: Parábola, 2012. 
KANT, Immanuel. Crítica da faculdade do juizo. Trad. de Valério Rohden e António Marques. 2. ed. Rio de Janeiro: Forense Universitária, 1995.

MINISTÉRIO DA EDUCAÇÃO; Secretaria de Educação Básica. Orientações curriculares para o ensino médio. Linguagens, códigos e suas tecnologias. Brasília: MEC, 2006.

MOREL, Marco. Sociabilidades entre Luzes e sombras: apontamentos para o estudo histórico das maçonarias da primeira metade do século XIX. Estudos Históricos, Rio de Janeiro, n. 28, p. 3-22, 2001.

PENNAC, Daniel. Como um romance. Trad. Leny Werneck. Rio de Janeiro: Rocco, 1993.

QUIJANO, Aníbal. Colonialidad del poder, eurocentrismo y América Latina. In: LANDER, Edgardo (Org.). La colonialidad del saber:eurocentrismo y ciencias sociales. Perspectivas Latinoamericanas. Buenos Aires: CLACSO, Consejo Latinoamericano de Ciencias Sociales, 2000, p. 201-246.

SALLENAVE, Danièle. "Nous, on n'aime pas lire". Paris: Gallimard, 2009.

TODOROV, Tzvetan. A literatura em perigo. Trad. Carlos Meira. Rio de Janeiro: DIFEL, 2009.

WHITE, Hayden. Tropics of Discourse. Essays in Cultural Criticism. 2. ed. Baltimore and London: The Johns Hopkins University Press, 1986.

WILLIAMS, Raymond. The long revolution. Londres: Pelican, 1980.

WOODMANSEE, Martha. The Author, Art, and the Market. Rereading the History of Aesthetics. New York: Columbia University Press, 1994. 


\section{Abstract \\ The studies of Letter in search of a reason for being}

The Studies of Letters have a long history and celebrated precursors, such as Plato, Aristotle and Quintilian. The period of its heyday coincided with the supremacy of researches in the field of the History of Literature, consecrating authors who became canonical. It currently experiences remarkable political exhaustion and loss of consumers, suggesting that its permanence depends on finding and establishing new partnerships.

Keywords: Letters; History of Literature; Teaching of Literature. 